\title{
Patients' knowledge and perceived reactions to medical errors in a tertiary health facility in Nigeria
}

\author{
*Ushie BA ${ }^{1}$, Salami KK², Jegede AS ${ }^{3}$, Oyetunde $\mathrm{M}^{4}$
}

1. Institute of Child Health, College of Medicine, University of Ibadan, Ibadan Nigeria.

2. Department of Sociology, University of Ibadan, Ibadan, Nigeria.

3. Department of Sociology, University of Ibadan, Ibadan, Nigeria.

4. Department of Nursing, College of Medicine, University of Ibadan, Ibadan, Nigeria.

\begin{abstract} Hospital, Nigeria. causes.

\section{Introduction}

Medical error is an umbrella term for all errors including mishandled surgery, diagnostic errors, equipment failures, and medication errors ${ }^{1}$. Woolf et al ${ }^{2}$ noted that medical errors are difficult to measure, not only because of inadequate reporting and varied definitions, but also because most incidents of medical errors are not single acts, but a chain of events. Thus, prescribing a wrong dose of a drug may be counted as a single error and named "error of prescription", but this error may have occurred because the patient's medical record contained an inaccurate body weight or because a laboratory report was missing $1,3,4$.
\end{abstract}

Background: Human errors in healthcare delivery pose serious threats to patients undergoing treatment. While clinical concern is growing in response, there is need to report social and behavioural context of the problem in Nigeria.

Objective: To examine patients' knowledge and perceived reactions to medical errors.

Methods: A cross-sectional survey was conducted using a semi-structured questionnaire was used to collect data from 269 in-patients and 10 In-Depth Interviews were conducted among health caregivers in the University of Calabar Teaching

Results: Majority (64.5\%) of respondents reported annoyance and disappointment with medical errors. Severity of error $(88.5 \%)$ and the perception of negligence mediated intention to litigate. Voluntary disclosure significantly reduced patients' intention to litigate caregivers ( $\left.\mathrm{chi}^{2}=3.584 ; \mathrm{df}=1 ; \mathrm{P}=0.053\right)$. Frustration/anger was not more likely to influence patient to litigate than feelings of resignation/forgiveness $\left(\mathrm{chi}^{2}=2.156 ; \mathrm{df}=1 ; \mathrm{P}>.05\right)$. Financial difficulties arising from error had an important influence on litigation. Health caregivers admitted possibility of errors; and insisted that although notifying patients/relatives about errors is appropriate, disclosure was dependent on the seriousness, health implications and the

Conclusion: Voluntary disclosure and teamwork is very important in dealing with medical error. The role of medical social workers could be important in the discourse and disclosure of medical error.

Keywords: Healthcare delivery, Malpractice litigation, Medical errors, Negligence, Voluntary disclosure, Nigeria. African Health Sciences 2013; 13(3): 820 - 828 http://dx.doi.org/10.4314/ahs.v13i3.43

\footnotetext{
*Corresponding author:

Boniface A. Ushie

Institute of Child Health

College of Medicine

University of Ibadan Ibadan

Nigeria

Tel: +2348050920109

Email boniface.ushie@gmail.com
}

In spite of the problematic associated with defining medical error, Kohn et al ${ }^{5}$ identified medical errors to include adverse drug events, improper transfusions, surgical injuries and wrong-site surgery, suicides, restraint-related injuries or deaths, falls, burns, pressure ulcers and mistaken patient identity. Studies ${ }^{6-9}$ have shown that majority of adverse incidents occurring in healthcare delivery are preventable mistakes. However, restraint-related injuries, deaths and suicides per se are not errors but consequences of neglecting to restraint the patients ${ }^{1}$ 10,11. Given this background, medical errors are therefore those mistakes that occur in the healthcare system, which ordinarily, if given immediate and adequate attention, could have been prevented. Oyebode's ${ }^{11}$ typology of medical error fits into a previous classification by Woolf et at ${ }^{2}$. While Oyebode ${ }^{11}$ and Woolf et af noted that medical error included diagnostic, treatment, preventive and communication-system failure errors, Woolf et af considered blood count failure as a fifth category of errors. Apparently, their classifications capture the 
varied types of errors committed in healthcare delivery. Medical errors pose serious threats to patients' lives and safety. It is estimated that no less than 44,000 to 98,000 patients in the USA die each year from medical errors ${ }^{12}$; and with the worst situation projected for developing countries with causes not just due to human mistakes, but also to factors such as faulty protocols in the health system 12 .

Changes in illness patterns were noted as potential sources of errors ${ }^{1}$. This consequently results in variations in errors which could either be treatment or preventive error ${ }^{13}$. Imam and Olorunfemi ${ }^{13}$ specifically found out that errors made in illnesses that deform the patients (e.g. stroke) often originate during clinical diagnosis. They reported a 13 to $43 \%$ misdiagnosis of stroke in Nigerian hospitals due to the lack of radiological tests, such as computerised tomography scans and the continued dependence on clinical diagnosis. Misdiagnosis has implications for the treatment offered ${ }^{14,15}$, and can lead to longer stays in hospitals and excess charges with the consequent depletion of patients' savings, which causes safety concerns and empoverishment ${ }^{16}$. The Quality Interagency Coordination Task Force ${ }^{17}$ reported that medical errors cost as much as \$US29 billion annually in lost income, disability and healthcare spending. The $\mathrm{QuIC}^{17}$ contends that the consequences of medical mistakes are often more severe than those in other industries because they lead to death or disability rather than inconvenience. An estimated 90,000 adverse clinical events, involving some 13,500 deaths, occur in the UK each year ${ }^{18}$. Consequentially, medication errors are an important cause of patient morbidity and mortality ${ }^{19}$. In addition, errors add workload and financial burden ${ }^{20 .}$."

Despite cases of medical error in Nigeria, limited information exists on medical negligence claims. In 2006, there was the case of a child who became HIV-infected through blood transfusion in a Nigerian teaching hospital even though both parents were HIV-negative. A commission of inquiry recommended the dismissal of the Chief Medical Director and payment of damages to the family ${ }^{21}$. Similarly, a drug manufacturing company was charged for medical malpractices for testing a drug on Nigerian children in 1996, which resulted in injuries, disabilities and deaths ${ }^{22}$. Although the rate at which medical negligence claims is reported in Nigeria, and Africa as a whole, is relatively low, previous reports have shown evidence of reactions to inadequate care and errors in treatment in Western countries from which lessons can be drawn. For instance, estimates show that between 1996 and 1997 medical negligence cost $£_{2} 235$ million $^{11}$, while negligence claims against general practitioners rose 13-fold between 1989 and $1998{ }^{23}$.

Reasons for instituting a perceived malpractice claim include if there was a poor relationship with the health care provider before the alleged error, if it involves television or media advertising by law firms and if there is an explicit recommendation by health providers to seek legal advice $^{11}$. A legal claim is also possible if there was an impression of not being kept informed by the health provider, and if it involves financial concerns. Even when responses of influential health practitioners have shown warnings like "to err is human, to cover up is unforgivable. To fail to learn is inexcusable"12, when caregivers commit errors, they do not like to reveal or disclose them or if they do, they provide incomplete information ${ }^{2}$. Caregivers have an ethical obligation to tell patients about significant errors they commit especially when such disclosure will benefit the patients ${ }^{24}$. Besides, it is a sign of respect for the patient's autonomy as dictated by ethical principles of justice. The emphasis on disclosure clearly points to patients' expectation that errors be openly disclosed ${ }^{24-26}$.

In a study that used a hypothetical scenario to describe a medical mishap, $71.4 \%$ of real patients were of the opinion that the care received by the hypothetical patient was bad or very bad, $60.2 \%$ considered that the patient was treated in unsafe conditions, and $25.5 \%$ would not recommend the hospital based on the scenario ${ }^{27}$. Studies that have explored people's perceptions about medical mishaps have established that the public's views are more negative when errors have severe health consequences $^{28,29}$, and when error are not disclosed to patients ${ }^{24,30}$. Patients' expectation of disclosure has motivated considerable recommendations for the disclosure of errors to patients as standard practice $^{31,32}$. However, there is limited evidence about the impact of such policy on malpractice litigation, and on the relationship between caregivers and patients ${ }^{27}$. Most of the available studies focused attention on clinicians' reports, thus, there is a knowledge gap on patients' understanding of errors or how they affect them. Yet, patients/relatives' reactions are important in the discussion of responses to medical errors. This study, therefore, examined patients' knowledge of medical errors, and what their reactions to it might be in Nigeria. 


\section{Methods}

This study utilised a descriptive cross-sectional designed and used a pre-tested semi-structured questionnaire to collect data from 269 in-patients at the University of Calabar Teaching Hospital (UCTH), Calabar, Nigeria. Respondents were recruited through a two-stage sampling technique involving the selection of 10 out of 15 units/wards in the hospital and 30 patients from each ward. The questionnaire contained items relating to knowledge, attitudes and practices of patients relating to medical error. Patients were asked to report on how they would feel should they detect errors committed by caregivers in their treatment. One health caregiver was selected from each ward, and interviewed, to document their perceptions of medical error in the hospital and reactions that follow errors from different sources.

Ethical approval was obtained from the ethical committee of the University of Calabar Teaching Hospital and verbal informed consent was obtained from all patients involved in the study. Two research assistants were trained on how to interview and administer questionnaire ethically and responsibly. To ascertain competence, a role-play session was organised as part of the training.

The interviews among the healthcare givers were conducted by one of the investigators. All data gathered were edited daily, coded and later processed into computer for analysis with the use of SPSS version 16.0 for quantitative data. Quantitative data were analysed using descriptive statistics and Chisquare test while content analysis was adopted for the qualitative data. Level of knowledge of error was derived by computing all 13 items on knowledge into a composite score with 1 and 13 as the lowest and highest obtainable scores, respectively. Low level knowledge was defined as $<$ the mean while high level knowledge was categorised as $>$ the mean.

\section{Results}

The mean age of respondents was 35.2 years, with 18 and 87 as minimum and maximum ages. Table 1 shows that female respondents made up $54.3 \%$ of the sample. The level of education of respondents ranged from no formal to tertiary. About one-third (37.9\%) had obtained a tertiary education, followed by those with secondary education $(30.5 \%)$ while $9.3 \%$ had no formal education. Less than half (46.1\%) of the respondents were single while $39.5 \%$ were married. Majority $(87.4 \%)$ of respondents were
Christians while the remaining $12.6 \%$ were adherents of traditional African religion.

Table 1: Socio-demographic characteristics of respondents

\begin{tabular}{|c|c|c|}
\hline Characteristics & Number & Percentage \\
\hline \multicolumn{3}{|l|}{ Sex } \\
\hline Male & 123 & 45.7 \\
\hline Female & 146 & 54.3 \\
\hline Total & 269 & 100 \\
\hline \multicolumn{3}{|l|}{ Age } \\
\hline 20 and below & 22 & 8.2 \\
\hline $21-30$ & 102 & 37.9 \\
\hline $31-40$ & 62 & 23.0 \\
\hline $41-50$ & 32 & 11.9 \\
\hline $51-60$ & 23 & 8.6 \\
\hline 61 and above & 28 & 10.4 \\
\hline Total & 269 & 100 \\
\hline \multicolumn{3}{|l|}{ Education } \\
\hline No formal education & 25 & 9.3 \\
\hline Primary & 60 & 22.3 \\
\hline Secondary & 82 & 30.5 \\
\hline Tertiary & 102 & 37.9 \\
\hline Total & 269 & 100 \\
\hline \multicolumn{3}{|l|}{ Occupation } \\
\hline Farming & 26 & 9.7 \\
\hline Business & 52 & 19.3 \\
\hline Civil service & 73 & 27.1 \\
\hline Student & 70 & 26.0 \\
\hline Unemployed & 48 & 17.8 \\
\hline Total & 269 & 100 \\
\hline \multicolumn{3}{|l|}{ Income/month } \\
\hline $\mathrm{N} 10,000$ \& below & 134 & 49.8 \\
\hline $\mathrm{N} 10,001$ - N20,000 & 38 & 14.1 \\
\hline $\mathrm{N} 20,001$ - N30,000 & 34 & 12.6 \\
\hline $\mathrm{N} 30,001-\mathrm{N} 40,000$ & 27 & 10.4 \\
\hline N40,001 \& above & 36 & 13.4 \\
\hline Total & 269 & 100 \\
\hline
\end{tabular}

About a quarter $(27.1 \%)$ of the respondents were civil servants, $19.3 \%$ were engaged in private businesses and $17.8 \%$ were unemployed. About half $(49.8 \%)$ of the respondents indicated that they earn less than 10, 000 Nigerian naira a month. Respondents who earned between 10, 001 and 20, 000 were $14.1 \%$ while $13.4 \%$ of the respondents earned above 40, 000 . 
Patients' awareness of medical errors was established in two ways: whether they had ever heard of medical error and whether they considered medical error a serious threat to patients' safety. Results in table 2 indicate that majority $(71.4 \%)$ of respondents were aware of medical error. Patients also indicated that medical errors pose serious threats to patients (44.6\%) though $34.6 \%$ did not conceived of error as a threat. Almost half (46.8\%) of the respondents reported that errors had been made in their care in the past. and became aware of those errors through personal detection $(21.9 \%)$, suspicion $(13.8 \%)$ and through voluntary disclosure by the healthcare givers $(11.2 \%)$. Overall, table 2 shows that there is no significant relationship between knowledge of error and gender of respondents $\left(\mathrm{chi}^{2}=1.264 ; \mathrm{df}=1\right.$; $\mathrm{P}>0.05)$. Also, that age of respondents did not significantly influenced their knowledge of error $\left(\mathrm{chi}^{2}=7.636 ; \mathrm{DF}=10 ; \mathrm{P}>0.05\right)$, although knowledge increased as level of education increased $\left(\mathrm{chi}^{2}=6.049\right.$; $\mathrm{DF}=3 ; \mathrm{P}<0.05)$.

Table 2: Patients' knowledge of medical errors by age, sex and educational attainment

\begin{tabular}{|c|c|c|c|}
\hline \multirow[t]{2}{*}{$\begin{array}{l}\text { Demographic } \\
\text { variables }\end{array}$} & \multicolumn{2}{|c|}{ Level of knowledge } & \multirow[t]{2}{*}{ Total } \\
\hline & above mean & below mean & \\
\hline \multicolumn{4}{|l|}{ Sex } \\
\hline Male & 56 & 67 & 123 \\
\hline Female & 64 & 82 & 146 \\
\hline \multirow[t]{2}{*}{ Total } & 120 & 149 & 269 \\
\hline & $\chi^{2}=1.264 ; \mathrm{df}=$ & $\mathrm{P}>0.05$ & \\
\hline \multicolumn{4}{|l|}{ Age } \\
\hline$<20$ & 11 & 11 & 22 \\
\hline $21-30$ & 47 & 55 & 102 \\
\hline $31-40$ & 30 & 32 & 62 \\
\hline $41-50$ & 11 & 22 & 32 \\
\hline $51-60$ & 11 & 12 & 23 \\
\hline $61+$ & 10 & 18 & 28 \\
\hline \multirow[t]{2}{*}{ Total } & 120 & 149 & 269 \\
\hline & $x^{2}=7.636 ; \mathrm{df}=$ & $; P>0.05$ & \\
\hline \multicolumn{4}{|l|}{ Schooling } \\
\hline No School & 7 & 18 & 25 \\
\hline Primary & 26 & 34 & 60 \\
\hline Secondary & 44 & 38 & 82 \\
\hline Tertiary & 43 & 59 & 102 \\
\hline \multirow[t]{2}{*}{ Total } & 120 & 149 & 269 \\
\hline & $x^{2}=6.0$ & $\mathrm{df}=3 ; \mathrm{P}<0.05$ & \\
\hline
\end{tabular}

Table 3 shows that negligence of duty by health caregivers was the perceived cause of error reported by most $(55.8 \%)$ respondents. Half $(50.8 \%)$ of the respondents indicated inadequate attention paid to patients, $32.0 \%$ blamed medical errors on patients' disobedience of medical instructions, while $39.4 \%$ and $31.6 \%$ identified inadequate health personnel and lack of teamwork even where opportunities for teamwork exist.

Also, patients' feelings pertaining to medical errors made in the course of their care were sought. Respondents were either "very annoyed", "annoyed", "disappointed" or "indifferent". Majority (98.5\%) of respondents had negative feelings about medical error with about half $(46.8 \%)$ maintaining that they would be very annoyed if they discovered the health workers made an avoidable mistake in their

African Health Sciences Vol 13 Issue 3 September 2013 treatment. Some $(17.5 \%)$ respondents would be 'annoyed', while $34.2 \%$ respondents would feel disappointed. Results also show that negative feelings (very annoyed, annoyed and disappointed) of respondents cumulated to $98.5 \%$.

Reactions to errors were reported including forgiveness to healthcare providers who committed the error. Only $3.7 \%$ would forgive completely, $28.3 \%$ would not forgive at all, while $44.2 \%$ of the respondents indicated that they would forgive, but not completely. It should be noted that $1.9 \%$ respondents would take action against such healthcare provider, while $6.3 \%$ would not take any action against any healthcare providers who committed errors while caring for them. Majority of the patients also indicated, in addition, that their responses would be dependent on the process by which the error came to be; whether it was by mistake 
or through negligence, nature of the error they experienced; and its implication on their health outcome.

Three conditions that might make patients want to take action were identified and presented to respondents for rating. Majority $(89.0 \%)$ of patients would base their reactions on the seriousness of the error, saying that they would take actions if the harm caused was serious. Moreover, 82.2\% would take action if the error was a result of negligence of duty. Some $(22.7 \%)$ would take action because of their personal dislike of the caregivers arising from their interactions during treatment or if the caregiver did not treat them in a likeable manner.
Respondents also reported the type of actions they would take if eventually they were to take actions. Table 3 also shows that about one-third (33.5\%) would want whoever committed the error suspended from work, $21.2 \%$ would sue the hospital, while $14.9 \%$ would sue the health care provider for compensation. Other reasons for taking action were: "to serve as a lesson for the healthcare provider in their future services to patients", "because patients demand quality services from healthcare providers" and "because there is need for justice for the harm caused by the error to the patient or their relatives". Majority $(89.2 \%)$ of respondents would like their caregivers to voluntarily report the mistake to them (table 4), and if they do, $64.7 \%$ would forgive them.

Table 3: Respondents' perception of causes of medical errors, actions to take and reasons for the choice of Action

\begin{tabular}{ll}
\hline Variable & Percentage \\
\hline Perceived cause of error* & \\
Inadequate attention to patients & 50.6 \\
Inadequate health personnel & 39.4 \\
Negligence of duty by health staff & 55.8 \\
Only a few nurses & 13.0 \\
No team work & 31.6 \\
Patients not obeying prescriptions & 32.0 \\
Errors are unavoidable & 7.1 \\
Actions to be taken in reaction to medical error & \\
Sue health caregivers for compensation & 14.9 \\
Sue to suspend the officer that committed the error & 33.5 \\
Sue the hospital where error is committed & 21.2 \\
Physically fight the health caregiver & 2.2 \\
Will resign to faith/do nothing & 26.8 \\
No response & 1.5 \\
Total & $\mathbf{1 0 0 . 0}$ \\
Reasons for taking the actions & \\
Need for justice for the harm caused by the error & 19.0 \\
Patients demand quality care from healthcare providers & 35.2 \\
To serve as lessons for caregiver in the future & 42.8 \\
No response & 3.0 \\
Total & $\mathbf{1 0 0 . 0}$ \\
\hline
\end{tabular}

*Multiple response variables

Table 4: Patients' willingness to be informed about errors and to recommend the caregiver

\begin{tabular}{lllll}
\hline Options & Yes & No & No response & Total \\
\hline Want to be informed of errors & & & & \\
Like to be informed & $240(89.2)$ & $20(7.4)$ & $9(3.3)$ & 269 \\
Would forgive if informed & $174(64.7)$ & $92(34.2)$ & $3(1.1)$ & 269 \\
Recommend caregivers/ hospital & & & & \\
Would recommend hospital & $84(31.2)$ & $182(67.7)$ & $3(1.1)$ & 269 \\
Would recommend caregiver & $35(13.0)$ & $221(82.2)$ & $13(4.8)$ & 269 \\
\hline
\end{tabular}


Health caregivers' perception of medical error Caregivers expressed their views on the enormity of the problems posed by medical error, their own susceptibility to committing error, error-reporting potentials, if any, and previous experience of reactions from patients. Caregivers felt that a lot of medical errors occur in Nigerian hospitals but also asserted that practitioners hardly accept that they make mistakes. Caregivers tended to feel that most of their colleagues were not well prepared for the job. A physician asserted that because mistakes in healthcare affect human life, errors should not be made at all due to the life-threatening impact they could have on patients. One male informant insisted that:

Believe it or not, mistakes in medical care are rampant but this will not be easy to uncover. The error comes in different ways that may not be exposed to patients. The prescription made by one doctor may be condemned by another. There is no system (forpatients) of detecting when errors are made... Since mistakes in health care affect human life, they should not be made at all. This is because once they are made, they are not easy to rectify.

Another physician identified misinterpretation of test result as a common error to physicians on daily basis and insisted that:

Mistakes are made every day in our hospitals. Sometimes, test results may be reading something else different from what a patient is suffering from. There was a case of a patient who was placed on a treatment for malaria and typhoid fevers when the treatment should have been for hepatitis.

Diverse opinions existed on the question of notifying the patients or their relatives about errors. Although caregivers claimed that it is most appropriate to inform the patients or their relatives about an error, they insisted that notification is dependent on the seriousness, health-problem implications and the source of the error. A nurse insisted that:

The right thing to do is to tell the patient or their relatives. But it also depends on the situation that revolves around the error; including the disposition of the patient and how amenable such error is. Hence, it is easier to report a mistake if the origin of it is the patient.

A physician corroborated the need to inform the patients about the error and situated this need on the ethics of working with human subjects. This view was aptly put thus:

Health care practitioners have a lot of responsibilities concerning medical error. The ethically correct thing

African Health Sciences Vol 13 Issue 3 September 2013 to do is to report the error to the patient and explain the implications, no matter the outcome of such a disclosure. The attitudes and reactions of the patients, and even the public, may not encourage disclosure, but it is still better to report than cover the fact.

\section{Discussion}

The consequences of medical error for patients' safety are critical ${ }^{33}$, yet, patients' and/or the public's knowledge about errors and their implication is poor ${ }^{2}$. This study reported a high rate of awareness of error as a serious threat to patients' safety. Although level of education impacted on the knowledge or awareness of threat of error, patients were less knowledgeable about the health implications. This affected their report of how they would react to errors. The highest proportion of patients in this study would be interested in seeing caregivers suspended if they made errors. Unlike previous studies ${ }^{11}$, which reported that financial consideration was the most important factor in negligence litigations, the present study found out that the seriousness of the error may be the most important factor in the intention to litigate. Of course, the seriousness of the error has implications for the amount of money that the affected patients or their families will spend for remedial purposes.

Patients in this study would like to be informed of errors made in their care and the potential adverse outcomes. This study found out that self-reporting of error to patients would not significantly reduce patients' intention to act against the caregivers or the institutions. However, notification of error by the caregivers would alleviate the seeming fears of possible reactions to error. This finding similar to the claim in the findings of Cleopas et $a l^{27}$ we found out that patients seem to have negative reactions toward medical error if the errors were detected by themselves, but with somewhat of more favourable views when self-reports were available. This is contrary to what was documented by Kraman and $\mathrm{Hamm}^{34}$ that voluntary disclosure of error reduces the incidence of malpractices litigations. In reality, taking action against the practitioner or the institution is not easy for patients. Not all patients are aware and knowledgeable about medical error, while majority, notwithstanding their level of education, do not know the procedure of instituting legal action when medical errors arise. Then, there is the burden to prove that the health outcome of the patient was a result of errors, and not just the necessary outcome based on the prognosis. 
Although information disclosure by health workers to patients is one of the pillars on which virile caregiver-patient relationship exist $\mathrm{t}^{35}$, this study found out that caregivers themselves do not accept their mistakes, especially, if the outcome of the error is grave. Woolf et at had already noted that caregivers do not necessarily accept that they make avoidable mistakes even when they recognised that caregivers do make mistakes. ${ }^{36,37}$ This sort of attitude and behaviour, on the part of the caregivers, do not only militate against error detection and management, but also violates the ethical tenets of caregiver-patient relationship. Caregivers do not accept and communicate their errors to patients because of a number of reasons, some of which may be difficulties in facing angry patients and their families, ${ }^{35,38}$ concern about the potential damage to their reputation ${ }^{38,39}$ and due to fear of malpractice litigation. ${ }^{35,38-40}$ Generally, caregivers leave out information that they consider may have negative impact on the patients. ${ }^{35}$

Public trust is essential in promoting public health ${ }^{41}$, and such trust is expected to be the bedrock for all caregivers. Proof of trust by physicians plays an important role in the public's compliance with public health interventions, influences the utilisation of modern health facilities and adherence to medical instructions on leaving the hospitals. Where public trust in caregivers is lost, especially as a result of medical error, rumours can spread easily, and can minimise, or even discourage, utilisation of health services from such facilities and can even 'spoil' the field, thereby leading to rejection of health interventions in the community.

The rejection might be compounded by a complex interplay of factors. These factors include lack of trust in modern medicine, poor political environment and religious inclination that prevent high patronage or use of orthodox treatment. Perceived betrayals by programmes like polio eradication in northern Nigeria had recorded a long history of boycott ${ }^{22}$ while such false perception and rumour may be difficult to stop. The role of social workers may be important in revelation of medical error and the support of affected patients to regain their normal lives.

The limitation of this study is that it did not specifically target patients who have suffered mistakes, and could not determine the prevalence of medical error. A study to determine prevalence would have required more than a survey of patients, and because the study did not work with "real victims" but on the expected reaction should an error occur, it is quite possible that findings may not be a good representation of real victims' reactions. However, the outcomes of this study are useful in that they provide evidence on the level of knowledge about medical errors and a picture of how patients and caregivers both react to medical errors.

\section{Conclusion}

Voluntary disclosure and teamwork is very important in dealing with medical error. The role of medical social workers could be important in the discourse and disclosure of medical error.

\section{References}

1. Ghaleb MA, Wong ICK. Medication errors in paediatric patients. Archives of disease in childhood - Education \& practice edition. 2006 ;91(1):ep20.

2. Woolf SH, Kuzel AJ, Dovey SM, Phillips RL, Jr. A String of Mistakes: The Importance of Cascade Analysis in Describing, Counting, and Preventing Medical Errors. Ann Fam Med. 2004;2(4):317-26.

3. Cook RI, Woods DD, editors. Operating at the sharp end: The complexity of human error. Hillsdale, NJ: Lawrence Erlbaum Associates; 1994.

4. Nolan TW. System changes to improve patient safety. BMJ. 2000;320(7237):771-3.

5. Kohn LT, Corrigan JM, Donalson MS. To err is human: building a safer health system. Washington, DC: National Academies Press; 1999.

6. Bates D, Boyle D, Vliet M, Schneider J, Leape L. Relationship between medication errors and adverse drug events. Journal of General Internal Medicine. 1995;10(4):199-205.

7. Bates DW, Cullen DJ, Laird N, Petersen LA, Small SD, Servi D, et al. Incidence of Adverse Drug Events and Potential Adverse Drug Events. JAMA: The Journal of the American Medical Association. 1995;274(1):29-34.

8. Holbrook J. The criminalisation of fatal medical mistakes. BMJ. 2003;327(7424):1118-9.

9. Yusuff K, Awotunde M. The frequency of drug history documentation in an institutionalized tertiary care setting in Nigeria. Journal of Pharmacy and Pharmaceutical Sciences. 2005;8(2):141-6.

10. Dean B, Schachter M, Vincent C, Barber N. Prescribing errors in hospital inpatients: their 
incidence and clinical significance. Quality and Safety in Health Care. 2002;11(4):340-4.

11. Oyebode F. Clinical errors and medical negligence. Adv Psychiatr Treat. 2006;12(3):2217.

12. PAHO. Patient safety: First do no harm. PAHO Newsletter. 2007.

13. Imam I, Olorunfemi G. Clinical Diagnosis of Stroke: Need for Audit. Annals of African Medicine. 2004;3(4):167-9.

14. Aiyesimoju AB, Osunsukun BO, Adeuja AO, Olumide A, Ogunseyinde AO. Misdiagnosis of stroke. African Journal of Medicine and Medical Sciences. 1983;12:107-12.

15. Ogun SA, Oluwole O, Ogunseyinde AO, Fatade B, Odusote KA. Misdiagnosis of stroke - a computerized tomographic scan study. West African Journal of Medicine. 2000;19:19-22.

16. Zhan C, Miller MR. Excess Length of Stay, Charges, and Mortality Attributable to Medical Injuries During Hospitalization. JAMA: The Journal of the American Medical Association. 2003;290(14):1868-74.

17. QuIC. Doing What Counts for Patient Safety: Federal Actions to Reduce Medical Errors and Their Impact. Rockville, MD: Quality Interagency Coordination Task Force2002.

18. Towse A, Danzon P. Medical negligence and the NHS: an economic analysis. Health Economics. 1999;8(2):93-101.

19. Stubbs J, Haw C, Taylor D. Prescription errors in psychiatry - a multi-centre study. Journal of Psychopharmacology. 2006;20(4):553-61.

20. Bracco D, Favre J, Bissonnette B, Wasserfallen J, Revelly J, Ravussin P, et al. Human errors in a multidisciplinary intensive care unit: a 1-year prospective study. Intensive Care Medicine. 2001;27(1):137-45.

21. Aladelokun D, Chiedozie I. Govt suspends four LUTH officials over baby infected with HIV. The Punch. 2006 June 21.

22. Jegede AS. What Led to the Nigerian Boycott of the Polio Vaccination Campaign? PLoS Med. 2007;4(3):e73.

23. Dyer C. GPs face escalating litigation. British Medical Journal. 1999;318:830-7.

24. Mazor KM, Simon SR, Gurwitz JH. Communicating With Patients About Medical Errors: A Review of the Literature. Arch Intern Med. 2004;164(15):1690-7.
25. Wu AW. Handling Hospital Errors: Is Disclosure the Best Defense? Annals of Internal Medicine. 1999;131(12):970-2.

26. Cantor MD. Telling patients the truth: a systems approach to disclosing adverse events. Quality and Safety in Health Care. 2002;11(1):7-8.

27. Cleopas A, Villaveces A, Charvet A, Bovier PA, Kolly V, Perneger TV. Patient assessments of a hypothetical medical error: effects of health outcome, disclosure, and staff responsiveness. Quality and Safety in Health Care. 2006;15:13641.

28. Blendon RJ, DesRoches CM, Brodie M, Benson JM, Rosen AB, Schneider E, et al. Views of Practicing Physicians and the Public on Medical Errors. New England Journal of Medicine. 2002;347(24):1933-40.

29. Schwappach DL, Koeck CM. What makes an error unacceptable? A functional survey on disclosure of medical errors. International Journal of Quality Health Care. 2004;16:317-26.

30. Witman AB, Park DM, Hardin SB. How Do Patients Want Physicians to Handle Mistakes? A Survey of Internal Medicine Patients in an Academic Setting. Arch Intern Med. 1996;156(22):2565-9.

31. Liang BA. A system of medical error disclosure. Quality and Safety in Health Care. 2002;11(1):648.

32. Gallagher TH, Levinson W. Disclosing Harmful Medical Errors to Patients: A Time for Professional Action. Arch Intern Med. 2005;165(16):1819-24.

33. Garbutt J, Brownstein DR, Klein EJ, Waterman A, Krauss MJ, Marcuse EK, et al. Reporting and Disclosing Medical Errors: Pediatricians' Attitudes and Behaviors. Arch Pediatr Adolesc Med. 2007;161(2):179-85.

34. Kraman SS, Hamm G. Risk Management: Extreme Honesty May Be the Best Policy. Annals of Internal Medicine. 1999;131(12):963-7.

35. 35. Ogundiran TO, Adebamowo CA. Surgeonpatient information disclosure in Southwestern Nigeria. Medical Principles and Practice. 2012 21:238-43.

36. Loren DJ, Garbutt J, Dunagan WC, Bommarito KM, Ebers AG, Levinson W, et al. Risk Managers, Physicians, and Disclosure of Harmful Medical Errors. Joint Commission Journal on Quality and Patient Safety. 2010;36:101-8.

37. Tagaddosinejad F, Mesri M, Sheikhazadi A, Mostafazadeh B, Farahani M. Disclosure of 
medical errors: attitudes of Iranian internists and surgeons. International Journal of Medical Toxicologyand Forensic Medicine. 2013; 3(1):20-27

38. Ibrahim A, Garba ES, Asuku ME. Challenges in disclosure of adverse events and errors in surgery: perspectives from sub-Saharan Africa. PanAfrican Medical Journal. 2012;12:82-7.

39. Kronman AC, Paasche-Orlow M, Orlander JD. Factors associated with disclosure of medical errors by housestaff. BMJ Quality \& Safety. 2012;21:271-8.
40. Burton WV, Parker RW. Psychological aspects of cancer surgery: surgeons' attitudes and opinions. Psychooncology. 1997;6:47-64.

41. Thompson A, Faith K, Gibson J, Upshur R. Pandemic influenza preparedness: an ethical framework to guide decision-making. $B M C$ Medical Ethics. 2006;7(1):12. 